\title{
A Survey of Practical Knowledge of Pre-service English Teachers in China
}

\author{
Mingmei Wang \\ Sichuan University of Arts and Science, Dazhou, China
}

\begin{abstract}
Based on interviews and questionnaires, this study investigates the current situation of practical knowledge of 96 senior normal English majors. Information to be gained includes the knowledge about self, discipline, students, educational situation and their beliefs in the essence of education. The results show that: 1) They have clear self-knowledge, but most of them lack teachers' professional identity. 2) Their disciplinary knowledge is generally limited, those with certain teaching experience are better off. 3) Their students' knowledge is seriously influenced by career hopes, those who are willing to be teachers are comparatively good at understanding their students. 4) Their perception of the educational situation of English is one-sided, social factors are totally ignored. 5) Their beliefs in the essence of English education are in the process of alternation between modern and traditional concepts. The findings of the survey are discussed and suggestions are made in this study.
\end{abstract}

Index Terms - pre-service English teachers, practical knowledge, current situation

\section{INTRODUCTION}

The quality of teaching and the success or failure of educational reform are closely related to teachers' professional quality. Teachers' practical knowledge is the knowledge that teachers actually use and display in the teaching practice. It is the knowledge base of teachers' professional development and the core of teachers' professional quality. It dominates teachers' teaching decisions and is the essential difference between excellent teachers, ordinary teachers and novice teachers. Teachers' practical knowledge is like the clearance node of teachers' professional development, which is a compulsory course for the future teachers who expect to do something great. English education in China, especially in the elementary education stage, is still dominated by classroom learning. Teachers are the main source of English input. Teachers' professional qualities directly affect the effectiveness of English teaching, thereby affecting the overall quality of English education in China. Normal college students are in the initial stage of the formation of teachers' professional quality. The practical knowledge they have acquired in the universities largely determines their future professional development and their ability to rapidly grow into expert teachers. Normal English majors will be the main force of English education. Therefore, to investigate the current situation of their practical knowledge, find out and solve the existing problems are of great significance for the sustainable improvement of English education.

\section{LITERATURE REVIEW}

The study of teacher's practical knowledge in the West begins in the 1980s. Based on a case study of an experienced secondary school teacher, Elbaz (1983) suggests that a teacher has a particular knowledge in a unique way, that is the practical knowledge. It is the integration of the teacher's professional theoretical knowledge, personal values and beliefs, characterized by specific practice situations and social environments, includes knowledge about the teacher himself, environment, subject content, curriculum and pedagogy. Her description of practical knowledge lays the foundation for the research in this field. From the mid-1980s to the mid-1990s, research is deepened. Connelly \& Clandinin (1985) not only explores how teachers' practical knowledge works in a particular situation, but also creates a new approach of narrative research. In the Middle and late 1990s, Dutch Scholars Beijaard \& Verloop (1999), Verloop \& Meije (2001) begin to turn their sights on the specific subject teaching, teacher evaluation, teacher education and so on, which further expands the research in this field. The research on practical knowledge of foreign language teachers begin in the mid 90s. Borg's research on grammar knowledge and grammar teaching knowledge of ESL teachers proves that teachers' subject knowledge has important relation with subject teaching knowledge (1998, 1999). Adopting the narrative method and referring to Elbaz's analytical framework, Golombek (1998) makes a case study of two ESL teachers who are both teaching assistants while studying for master's degree in Teacher Education, revealing the personal practical knowledge constructed by the two teachers in the process of learning..

The study of teacher's practical knowledge in China begins in the 21st Century. In theoretical research, the team led by Professor Chen Xiangming (2011) has made a comprehensive and systematic local research. The definition of practical knowledge has been revised to read: "Teachers' understanding of education and teaching formed after reflecting and refining their own educational and teaching experience, and expressed through their own actions" (p. 64), and it includes five types of content: knowledge about self, subjects, students, educational situations and beliefs in the essence of education. Among them, self-knowledge refers to teachers' self-identity, self-understanding and self- 
positioning, values and so on. Disciplinary knowledge refers to teachers' subject knowledge, curriculum knowledge and pedagogical knowledge. Knowledge of students refers to the teachers' understanding of the students' learning ability, motivation, cognitive form, etc.. Knowledge about educational situation refers to teachers' perception of social and cultural background, such as classroom situation, school atmosphere, cultural tradition, etc.. The belief in the essence of education refers to the teacher's cognition of the purpose of education and what is good education. Her monograph also elaborates in detail on the forms, elements and media of teachers' practical knowledge, which marks the beginning of the in-depth development of domestic research in this field. In practical research, the research focuses on demonstrating the role of teachers' practical knowledge, the relevance of practical knowledge to teaching situation and teaching experience, the effectiveness of solving practical problems in teaching and so on (Wang Yan, 2013). There have also been some qualitative studies in the field of foreign language education. By describing the development of an expert English teacher from novice to expert, Li Dehua (2005) reveals the factors and opportunities that affect the acquisition and updating of teachers' practical knowledge. Wang Yan (2011) reveals the composition, characteristics, sources and influencing factors of practical knowledge of excellent foreign language teachers.

Existing research has made people fully aware of the importance and uniqueness of teacher's practical knowledge, also provides theoretical basis for analyzing teachers' teaching behavior and how to optimize classroom teaching. However, there are the following limitations: First, the systematic study of foreign language teachers' practical knowledge is not rich enough. Foreign language teaching is different from other disciplines. Foreign language is not only the content of the subject, but also the teaching tool. It also lacks social culture, language environment and pragmatic significance. Therefore, it is theoretically necessary to study the practical knowledge of foreign language teachers on the basis of subject characteristics and unique curriculum situation. Second, research on the construction of pre-service teachers' practical knowledge is almost blank. Applying existing research results to teacher education is not only the expansion and deepening of research in this field, but also the full play of its practical value. In view of this, this paper will investigate the current situation of normal English majors' practical knowledge, and provide some reference for the effective English teacher training.

\section{METHOD}

\section{A. Respondents}

The respondents are 107 senior normal English majors from 3 comprehensive universities in Sichuan. They had just finished their two-month internship in the middle schools. The survey was conducted in the first week after they returned to the universities.

\section{B. Survey Tools}

Interviews and self-made questionnaires are used as the survey tools. The interview focuses on students' reflection on internships, lessons learned from teachers' learning process and so on. The questionnaire consists of two parts. The first part is the basic information of students. The second part includes 40 questions (30 multiple-choice questions, 10 shortanswer questions), which are set up according to the content type of teachers' practical knowledge put forward by Chen Xiangming (2011). Questionnaires were distributed through professional survey software, and respondents answered online by mobile phone or computer. A total of 96 valid questionnaires were collected from the survey. The contents of the questionnaire are as follows.

1. Self-knowledge. Would you like to be an English teacher? Do you think it is meaningful to become an English teacher? What kind of job would you like to do? Do you think you are qualified to be an English teacher? Do you know your own character and teaching ability? Can you give full play to your strengths and avoid your weaknesses in the teaching? Are you willing to accept the feedback from students and other teachers? Can you learn from your mistakes and adjust your attitude and behavior in time?

2. Knowledge about the discipline. Do you think you have enough knowledge of English? Do you think you have enough knowledge in related fields? Do you understand the development process and principles of secondary school English curriculum? Do you know the criteria for selecting the content of secondary school English textbooks? Do you know the relationship between the knowledge points in secondary school English textbooks? Do you know how the progress of secondary school English in different grades is arranged?

3. Knowledge about the students. Do you think the statement that there are only teachers who can't teach well, no students who can't learn well is correct? Is there any possibility of counterattack for the students with learning difficulties? Do you think students can be judged by one or two things? What do you think are the factors that affect middle school students' English learning? How do you think the relationship between teachers and students should be handled? Do you know the motivation for most middle school students to learn English? Do you know the English learning strategies used by the middle school students?

4. Knowledge about the educational situations. Can you seize and make use of educational opportunities that arise occasionally in class? Do you know the current teaching methods used by middle school English teachers? Do middle school English teachers pay more attention to the memory of knowledge or the use of language? Do you know the major difficulties faced by middle school English teachers nowadays? What support does the local education bureau 
have for English teaching? What impact will the National Matriculation English Test (NMET) reform bring to the middle school English teaching? Do you know the specific content of the new college entrance examination?

5. Beliefs in the essence of education. Do you know the purpose of English teaching? What do you think is the standard to measure the success of an English teacher? Is teaching vocabulary and grammar English teacher's sole job? The only characteristic of English is instrumentality, isn't it? If not, what else? Do you pay more attention to teachers' teaching or students' learning? When designing teaching plans, would you take students' response into consideration? What kind of relationship should be between English teachers and students in class? What do you think the middle school English teaching should be based on? What do you think the middle school English teaching should be centered on? How do you teach vocabulary? How do you teach the text?

\section{RESUlts AND Discussions}

\section{A. Self-knowledge}

Except $4 \%$ of the normal English majors admit that they are not sure what career they would take in the future, the others have clear self-knowledge and career hopes. Unfortunately, only $35 \%$ of them are willing to be English teachers, $61 \%$ of them are unwilling to engage in teaching profession. Those who are willing to be English teachers believe that teachers' work can not only bring them a sense of accomplishment, but also has the power to affect students' growth and even students' whole life. They believe that they will be able to guide and promote students to get progress in English learning. They also express their willingness to receive negative feedback from students and other colleagues and feel that negative feedback is like a mirror in which they could most directly and effectively see their teaching flaws. They also have a positive attitude toward mistakes in teaching. They regard mistakes as the only way for teachers to grow up and deem that only by constantly learning from mistakes can they improve their teaching ability faster and better. They believe that they can make full use of their strengths and avoid the weaknesses in teaching, but no one thinks that he has the ability to design a constructive lesson plan. It is acceptable. To design a constructive plan requires not only the ability to refine and grasp knowledge, to be familiar with the arrangement of textbooks, curriculum standards and knowledge in other fields, but also the ability to combine these knowledge with the actual needs of students. Normal students are still in the initial stage of teacher training, they need constant practice and reflection before they get to that height. Among those who are not willing to be teachers, a few are for their own defects. They consider that they lack patience and knowledge, do not like the noisy environment in the elementary and secondary schools. But more than half of them do not choose to be teachers because of their prejudice against teachers' profession. Some believe that firstclass students learn science, second-class students learn arts, third-class students learn to be teachers, being a teacher means being a depised figure in their eyes. Others think that teachers' salaries are too low and teachers' work is quite boring and tiring. They tend to engage in jobs with high wages and good working conditions. Comparing the above figures, we can see that influenced by the unhealthy social atmosphere in the current society, the values of most normal students have become materialized. It also reflects that the environment in which the normal students live is not conducive to the formation of correct Three Outlooks. From the perspective of social environment, the pursuit of fame and fortune prevails. From the perspective of schools, more attention has been paid to the imparting of practical knowledge and skills, while the cultivation of spiritual culture has been neglected seriously. It is well known that learners' inner feelings, beliefs and values directly affect the quality and quantity of practical knowledge learning. If the values of normal students can not be corrected in time, even if they choose the teacher profession, they can only become teaching machines rather than educators, which is contrary to the purpose of our teacher education. Therefore, how to make normal students correctly view the profession of teachers and correctly measure the value and significance of being a teacher should be the primary issue for teachers' educators to consider.

\section{B. Knowledge about the Discipline}

The disciplinary knowledge of the normal English majors is very scarce. Those who have a good grasp of English knowledge account for $48 \%$, but self-examination shows that $17 \%$ of them have mastered the relevant knowledge. That is to say, only $17 \%$ of the students are qualified to become English teachers from the point of view of knowledge. The fact is that all the $17 \%$ have teaching experience in tutoring or training classes and have a deep understanding of the importance of practical knowledge. While the rest generally have the following ideological errors: "As long as I have a solid knowledge of English, I can become good English teachers." "Teaching knowledge is very simple, it won't be late to learn when I start teaching". "Courses such as pedagogy are boring and I do not want to learn". No matter whether they have part-time teaching experience or only internship experience, they do not understand the process and principle of English curriculum development, nor the schedule of teaching in different grades. However, among the normal students who have done part-time teaching, 3\% know the selection criteria of textbook content and 5\% know the relationship between knowledge points. These figures show that the current construction of English teacher education is weak, and the teacher education curriculum is not comprehensive. Normal students do not have the opportunity to conduct a comprehensive understanding and systematic analysis of secondary school English textbooks. Even though some students have some familiarity with the textbooks in the process of tutoring or teaching in training classes, they are still limited to the textbooks or contents they have been exposed to, and fail to have an in-depth understanding of the arrangement and compiling principles of English textbooks in secondary schools. This phenomenon also reflects the 
stubborn disease in teacher education: The theory is divorced from practice and lacks the situational characteristics, which makes the theory teaching empty and abstract. Consequently, the normal school students have no interest in the theory study. The solution of the above problem depends on the following two aspects of the work of teacher educators. First, exploring the teaching mode of combining theoretical knowledge with practical knowledge, so as to promote normal students to realize teachers' learning and professional development by studying their own practical experience and improving teaching behavior. Second, improving the curriculum system to make it closely related to the reality of basic education and enhance the practicability of the courses offered so as to arouse students' interest in learning, thereby increasing the knowledge reserve of normal students.

\section{Knowledge about the Students}

The data from this section shows that career hopes of normal students affect their understanding of students. Those who are unwilling to be teachers have a one-sided and passive view of students. They think that "There are students who can't learn anything well." "It's hard for the students with learning difficulties to have an opportunity to counterattack because of the weak foundation of English." "Behavior is the embodiment of thought, and contingency can reflect the mind of students." "Teachers' authority should be maintained in teacher-student relationship." "Nearly all the middle school students' motivation is to get higher scores." "I don't know students' learning strategies." Those who are willing to teach are more comprehensive and active in their understanding of students. It is believed that "genuine love for students and appropriate teaching methods will benefit all students." "Students with learning difficulties are likely to counterattack if they find the right learning method." "It is a continuous process to recognize students". "It is necessary to observe for a long time to get a relatively objective evaluation of students." "There are many factors that affect English learning, such as scores, interests, family education, personality, etc." "The relationship between teachers and students should be mutual respect, democratic and equal." "Different students have different motivations." "Students with different academic achievements have different English learning strategies." These completely different answers show that professional identity determines work attitude. The normal majors who are willing to teach think it is a happy and meaningful thing to get along with students. They spend a lot of time talking, communicating and doing sports with the students after class, so that they can get to know students more truly and comprehensively. At the same time, their love for their careers also enables them to take a positive view of their students. Normal students who are unwilling to teach hold the attitude of fulfilling the task and have little communication with students in their free time, which definitely leads to their prejudices and lopsided views. Love is the motive force of doing everything well. Without love, there is no intention and dedication. Teachers are faced with students, in addition to knowledge imparting, more emotional input is needed. Love and other non-academic factors are an important factor restricting a teacher to become a real teacher. Therefore, the first and most important step in teacher education should be to make normal students view the profession of teachers positively and correctly, cultivate their sense of professional identity and pride, and stimulate their inner love for the profession.

\section{Knowledge about the Educational Situation}

Answers to this part of questions indicate that normal students have not got an overall view of the educational situation of English. Only $8 \%$ of the normal majors think that they have the ability to seize and utilize occasional educational opportunities in class. The interview and basic information prove that language proficiency of these students is high. To seize and utilize occasional educational opportunities in class is an instant generating ability (Wang Qiang, 2009), it needs not only teacher's wisdom and solid subject knowledge, but also a deep cultural literacy. This is an acceptable result since it is a high requirement for the in-service teachers, let alone the pre-service teachers who haven't teaching experience. After self-examination, all the respondents think that they know the teaching methods and focus of middle school English teachers and nearly half know the main problems faced by middle school English teachers. But almost no one has paid any attention to the social and school environment in which English teaching is conducted. Only three normal students think that they probably know a little about the new policy of the college entrance examination of English, but they are not clear about its impact. It can be seen from the above data that normal students lack the awareness of paying attention to the educational situation from the macro level. They only notice the most intuitive part of the teacher and lack understanding of the general environment of education, which shows that normal school students do not have the ability to fully understand things. This defect is closely related to their learning habits. The spoon feeding education mode has been in our country for a long time. Until now, it is still the norm of primary and secondary education. In this way, students are only good at memorizing textbook knowledge mechanically, and lack the most precious independent thinking ability and critical thinking. At the same time, in the eyes of parents and teachers, academic achievement is the only criterion to measure children. Under the influence of this idea, children have gradually become indifferent to the things which are not directly related to them. Do not keep your ears out of the window, just concentrate on the books of the sages and thus to pursue higher scores has become the only major event in their students' lives. This severely limits children's vision, imagination and thinking. As a result, they believe that teaching is a very simple matter, involving only teachers and students, while fail to take into account the impact of politics and social environment such as policies and guidelines on teaching. Social culture theory, the main theory of second language teacher education, holds that teacher learning is a process of continuous dialogue between teachers and social environment so as to acquire self-knowledge, student knowledge, subject knowledge, curriculum knowledge and 
environmental knowledge (Johnson, 2006). In this process, the interaction of internal and external factors affects the process and results of teachers' learning and development. Without dialogue with the environment, how can the teacher get the proper cognition and growth? Foreign language teaching is a process composed of many factors, involving not only teachers and students, but also foreign language education policies and their implementation. The purpose of education, educational policy and training objectives affect English teaching in a big way, and the opening, opening hours, purposes and requirements of English classes are all subject to them (He Guangzheng, 2011). How to perceive and interpret the educational situation is bound to affect teachers' teaching strategies. The cultivation of thinking ability is a long process. This work should be started from the initial stage of education. However, the current normal school students are already in a state of lack of this ability. What the teacher education can do is to make every effort to make up for it.

\section{E. Beliefs in the Essence of English Education}

The results of this section reflect that the majority of normal students' understanding of the essence of English education is vague, even contradictory. For example, although $98 \%$ of the respondents believe that students' learning is more important than teachers' teaching, 62\% of them usually do not consider students' needs and possible reactions when designing teaching plans. Although $69 \%$ know that English has both instrumental characteristics and cultural factors, $76 \%$ still believe that to memorize the language points is the central task of English learning in middle schools, even more than $79 \%$ think that the job of English teachers is only to teach language knowledge. More than $82 \%$ of the respondents surveyed know the purpose of English teaching, but 92\% believe that students' test scores are the only criterion for teachers' success. When answering the question of how they teach words, more than half of the normal students say that they would ask their students to read the new words repeatedly, only a small number of normal students choose to use word-formation to split words to help students understand and remember. In dealing with the text, $69 \%$ of the students adopt the grammar-translation method, explaining the meaning and grammatical phenomena of the text word by word, sentence by sentence. Only $25 \%$ of the students deal with the text by asking questions, discussing and so on. When asked why they taught words and texts in this way, they answer that they themselves were taught like this. These normal students have received the traditional teaching methods since they began to learn English in junior middle school. During the six years of English learning, their cognition of teaching has been deeply rooted in the traditional educational ideas. In the meantime, the advanced educational concepts on foreign language teaching have not been involved in their professional learning in universities. This phenomenon is worthy of careful consideration. Currently, many teachers' colleges use large amounts of resources in the course of general teacher education, but many courses are not closely related to the specialty of foreign language teachers (such as how to teach listening, reading, writing, oral English and other specialized skills), which surely leads to the vague belief of normal students in the nature of foreign language education. What is worth paying attention to is that in recent years, great changes have taken place in basic English education and foreign language education policies. If we still stay in generalizing education instead of carrying out some targeted courses, the future English teachers are very likely to continue to transplant their learning experience into their future teaching, which is not conducive to helping them face new challenges of the new era and meet new needs of society. From these contradictory data, we can see that the normal English majors are still in the process of alternation between modern and traditional concepts. Their belief in the nature of English education has not yet been formed. Teacher educators should seize the last opportunity to make normal students correctly understand the nature of English education, so as to assist them to form a correct view of teaching and better guide their teaching practice.

\section{SugGestions}

From the above survey data, a conclusion can be drawn that there is a big gap between the practical knowledge of the normal English majors and the actual needs, which shows that there are still great defects in our teacher education. There are two most prominent problems. One is the misunderstanding and prejudice towards teachers' profession caused by incorrect values, the other is teacher training is seriously divorced from the reality of basic teaching. Based on the conclusions and discussions, the following suggestions are made:

First, attach importance to guiding normal students to establish correct values. A remarkable new trend has emerged in education around the world: from ability-oriented to values-oriented. Values are the criteria for people to analyze and measure the world, also the criteria and norms for group members or social members to consciously regulate social behavior and social life. The purpose of education is not only to impart knowledge and skills training, but also to help students set up correct values, pay attention to the inner feelings and personality, achieve the harmony of human spirit and material unity. Foreign language education in our country emphasizes more on basic knowledge and basic skills training. Schools are filled with an atmosphere of eagerness for quick success and instant benefit. Students lack humanistic care, correct values for the development of the world, concern and reflection on the things around them. Although professional knowledge education can be provided, it will only make people a useful tool, not a person with harmonious development. Teachers are the disseminators of advanced ideas and the guidance of students' healthy growth. Only when teachers themselves have the correct values can they bear the epochal responsibility of spreading ideas, shaping souls, shaping lives and shaping new people. Therefore, the author suggests that normal universities can 
help students establish correct values from various aspects. For the university management staff, they should work under the guidance of the philosophy of people-oriented education and try to construct a campus culture with humanistic spirit. For the teaching staff, it is an unshakable duty to shoulder the responsibility of educating students in the process of imparting knowledge. At the same time, the undergraduate tutorial system can be implemented to increase the connection between teachers and students. As the relationship between teachers and students draws closer, students will learn how to appreciate and give the warmth and love from and to others.

Second, keep intimate links with basic education. For normal school students, maintaining close contact with basic education is a feasible way to combine educational practice with educational theory, which helps them form educational beliefs and have a deep understanding and grasp of education and teaching. Teacher learning is not a simple linear process from learning theoretical knowledge to learning practical knowledge (Brouwer \& Korthagen, 2005; Black \& Halliwell, 2000), but a gradual process based on the experience gained in practice and effective reflection on the memory of theoretical knowledge (Avalos, 2011). There are usually two ways to acquire practical knowledge: teachers' individual educational practice activities and others' educational and teaching practice or experience. Therefore, in addition to the most commonly used probation and internship, the opportunities ought to be increased for normal school students to contact the reality of basic education by means of high-quality class observation and case analysis etc., which can not only make normal students realize the gap between their own ability and the actual needs, but also arouse their consciousness of combining practice with theory.

Third, perfect the curriculum. The importance of curriculum is self-evident. It is not only related to whether it is conducive to helping students establish an accurate outlook on life, whether they have access to the reality of basic education, but also related to the integrity of teachers' knowledge, the teaching decision-making and teaching effect. The curriculum system usually consists of three parts: knowledge, skills and attitudes. How to arrange the order of the three and what courses to offer determine the focus of teacher education and the quality of teachers. Influenced by traditional educational ideas, the courses currently offered attach more importance to knowledge than skills, to skills than attitudes. In the Internet age, teachers are no longer the only possessors and providers of knowledge, but the organizers and guiders of classroom learning. A positive attitude is the key to a better life and a worthwhile career. Therefore, knowledge should no longer occupy the first place in curriculum in this learning society. Accordingly, attention should be paid to the following three points in the course design. First, make the emphasis of curriculum be in line with the changes and demands of the times. Namely, attitude should go first, then skill and knowledge. Given the lack of Three Outlooks construction, courses that can cultivate humanistic quality, such as historical research, social analysis, foreign culture, moral rationality should be offered. Second, courses such as English subject standard and the analysis of middle school English textbooks should be added in order to help the normal students get familiar with the new curriculum reform of basic education and deepen their understanding of subject curriculum standards and textbooks. Third, increase the credits in practice appropriately and set up more forms of practice, for example, the simulation teaching in microteaching, being substitute teachers or tutors, comparison and simulation on the information network, etc. to assist normal students acquire practical knowledge in the process of doing.

\section{ACKNOWLEDGMENTS}

This work is supported by the ninth China Foreign Language Education Fund. (Project No.: ZGWYJYJJ2018B100)

\section{REFERENCES}

[1] Avalos, B. (2011). Teacher professional development in teaching and teacher education over ten years. Teaching and Teacher Education, 27.1, 10-20.

[2] Beijaard, D., Driel, J. V. \& Verloop, N. (1999). Evaluation of Story-line Methodology in Research on Teachers' Practical Knowledge. Studies in Educational Evaluation, 25.1, 47-62.

[3] Black, A. 1. \& Hailliwell, G. (2000). Accessing practical knowledge: How? Why? Teaching and Teacher Education, 16.1, 103115 .

[4] Borg, S. (1998). Teachers' pedagogical systems and grammar teaching: A qualitative study. TESOL Quarterly, 32.1, 9-37.

[5] Borg, S. (1999). The use of grammatical terminology in the second language classroom: a qualitative study of teachers' practice and cognitions. Applied Linguistics, 20.1, 95-126.

[6] Brouwer, N. \& Korthagen, F. (2005). Can teacher education make a difference? American Educational Research Journal 42.1, 153-224.

[7] Connelly, F. M., \& D. J. Clandinin. (1985). Personal practical knowledge and the modes knowledge: Relevance in teaching learning. In E. Eisener (Ed.), Learning and Teaching the Ways of Knowing. Chicago: University of Chicago press, 174-198.

[8] Cheng Xiangming. (2011). Bridging Praxis and Theory: A Study of Teachers' Practical Knowledge. Beijing: Educational Science Publishing House.

[9] Elbaz, F. (1983). Teacher Thinking: A Study of Practical Knowledge. New York: Nichols Publishing Company.

[10] Golombek, P. R. (1998). A study of language teachers' personal practical knowledge. Modern Language Journal, 83.3, 35-50.

[11] He Guangzheng. (2011). Theory and practice of English Teaching Methodology. Guang Zhou: Jinan University Press.

[12] Johnson,K.E. (2006). The sociocultural turn and its challenges for second language teacher education. TESOL Quarterly, 40.1, 235-257. 
[13] Li Dehua. (2005). The construction of novice teachers' practical knowledge: Analysis of teachers' life history. Education Story, 12, 26-30.

[14] Verloop, N., J. V. Dreil \& P. Meijer. (2001). Teacher knowledge and the knowledge base of teaching. International Journal of Educational Research, 35.5, 441-461.

[15] Wang Qiang. (2009). Presupposition and generation in English Classroom Teaching. English Teachers, 8, 18-21.

[16] Wang Yan. (2011). A case study of practical knowledge of excellent foreign language teachers. Theory and practice of foreign language teaching 1, 68-76.

[17] Wang Yan. (2013). Review and Prospect of Foreign Language Teachers' Practical Knowledge Research. Development and Assessment of Higher Education, 29.6, 87-104.

Mingmei Wang was born in Dazhou, China in 1976. She received her M.A. in linguistics and applied linguistics from Chongqing University, China in 2008.

She is currently an associate professor in the School of Foreign Languages, Sichuan University of Arts and Science, Dazhou, China. Her research interests include applied linguistics and teacher education. 